\title{
ANÁLISE DO PERFIL LONGITUDINAL DO ALTO CURSO RIO DAS VELHAS - OURO PRETO, MG
}

\author{
Vinícius de Oliveira Maruschi ${ }^{(a)}$, Anna Carolina Barcelos ${ }^{(b)}$ \\ (a) Inatituto de Geografia/Universidade Federal de Uberlândia, vinicius.maruschi@ufu.br \\ (b) Instituto de Geografia/ Universidade Federal de Uberlândia, barceloscarolina@hotmail.com
}

\section{EIXO: SISTEMAS GEOMORFOLÓGICOS: ESTRUTURA, DINÂMICAS E PROCESSOS}

\section{Resumo}

O presente trabalho tem como objetivo analisar o perfil longitudinal, indice de Hack e litologia de oitenta quilômetros da nascente do Rio das Velhas, situado dentro da bacia Hidrográfica Alto Curso Rio das Velhas. Para tanto foi realizado o cálculo do indíce de Hack, tilizando ferramentas acessíveis como os softwares Google Earth e Excel e relacionando os valores obtidos com a litologia do canal. Foi elaborado um mapa de unidades geológicas que contem o trecho e a rede de drenagem da bacia analisada comparando com a litologia presente, para ficar visivel e mais clara a análise e interpretação dos dados obtidos. $\mathrm{O}$ estudo mostrou os locais do trecho analisado onde existem a maior variação no valor do indice de Hack.

Palavras chave: Indice de Hack, Geomorfologia, Geomorfologia Fluvial, Bacia Hidrográfica.

\section{Introdução}

Utilizando os Softwares Excel, Google Earth Pro, e ArcGis 10.2.2, realizou-se a análise de 80 quilômetros da nascente do Rio das Velhas, situado dentro da bacia Hidrográfica Alto Curso Rio das Velhas. A partir disso, coletamos dados para a análise e elaboração de tabelas, gráficos e mapas, que foram essenciais para a obtenção dos resultados deste presente trabalho. Para isso, foi realizada uma pesquisa teórica com o objetivo de melhorar os conhecimentos e alcançar resultados melhores.

O alto curso deste rio, que é o maior afluente do São Francisco, encontra-se nas proximidades da cidade de Ouro Preto, MG, situado no Parque Natural Municipal das Andorinhas, que faz parte da Área de Proteção Ambiental Estadual da Cachoeira das Andorinhas (Figura 1), nas coordenadas: 20²2'6.78"S. Esse trabalho tem como objetivo analisar desde a nascente até o exutório previamente definido, nas coordenadas: $43^{\circ} 27^{\prime} 53.57^{\prime \prime} \mathrm{O}$. 

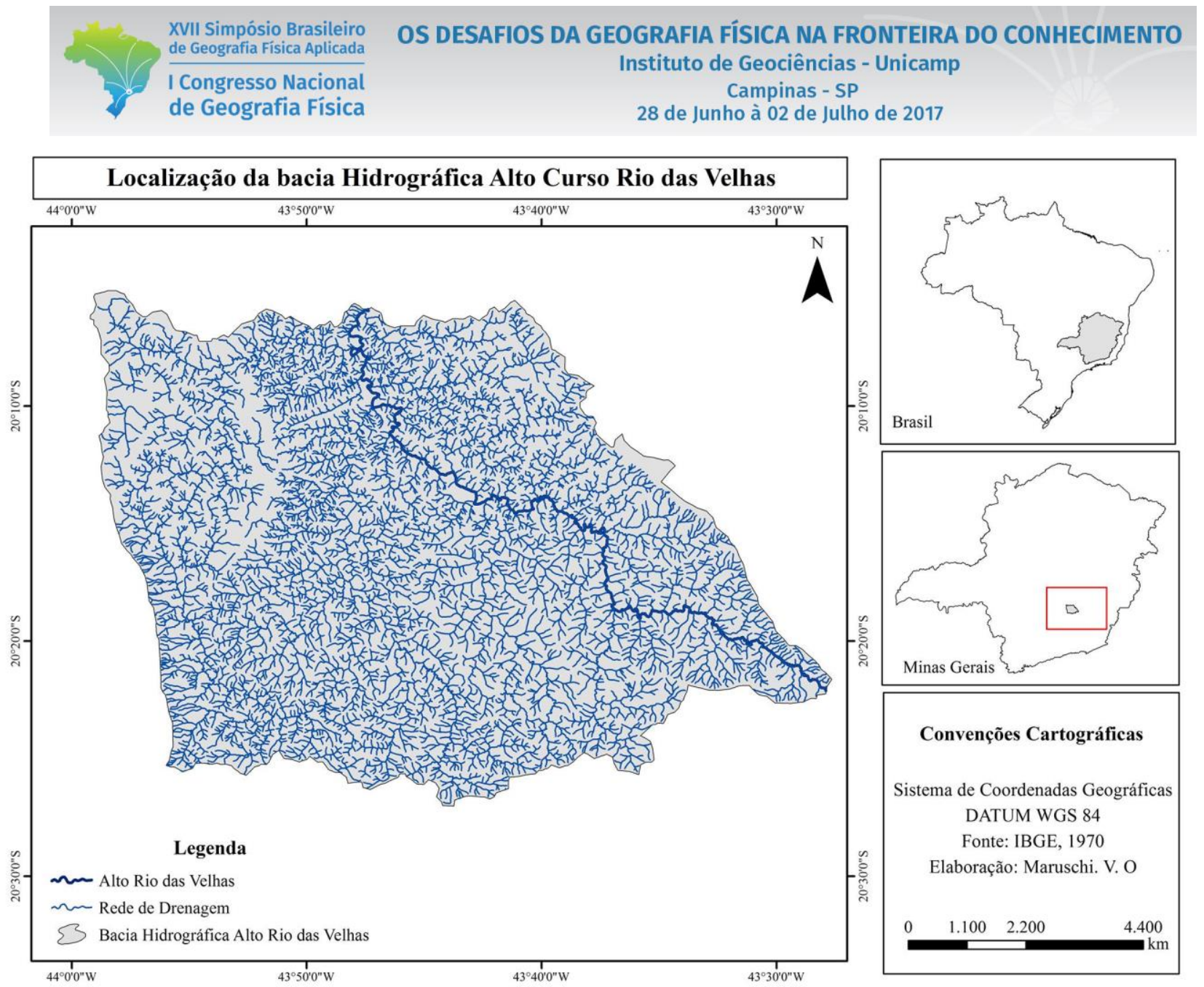

Figura 1 - Localização da bacia Hidrográfica

Conforme a figura 2, podemos observar que o trecho de 80 quilômetros analisados da Bacia Hidrográfica Alto Curso do Rio das Velhas, está localizado sobre quatro tipos de litologias diferentes. A litologia presente no inicio e na maior parte do percurso do canal é o Supergrupo Rio das Velhas, Grupo Nova Alto Curso Rio das VelhasLima, segundo CODEMIG (2014) supergrupo e grupo são encontradas rochas metaultramáfica, metamáfica tholeiíticas, metabasalto komatiítico e metavulcânica félsica, formações químico-exalativas, -Formações Ferríferas Bandadas (FFB) e xisto, rochas essas que são metamórficas e do período mesoarqueano. O segundo tipo de litologia encontrada no trecho é a do Complexo Bação, sendo Ortognaisses bandados tipo tonalito-trondhjemito-granodiorito (TTG), com intercalações de anfibolito e metaultramáfica, rochas pertencentes ao período Mesoarqueano e de características Metamórficas. O terceiro grupo de rochas encontradas é de característica Ígnea pertencente ao período Mesoarqueano e as rochas presentes são: Granitoides potássicos intrusivos em gnaisse TTG do Complexo Bação, litofácieis granitoide potássico. Já a quarta e última litologia encontrada no canal é composta pelos Supergrupo Rio das Velhas, Grupo Maquiné onde é identificado Quartzito e metaconglomerado polimítico, rochas metamórficas do período Mesoarqueano. 


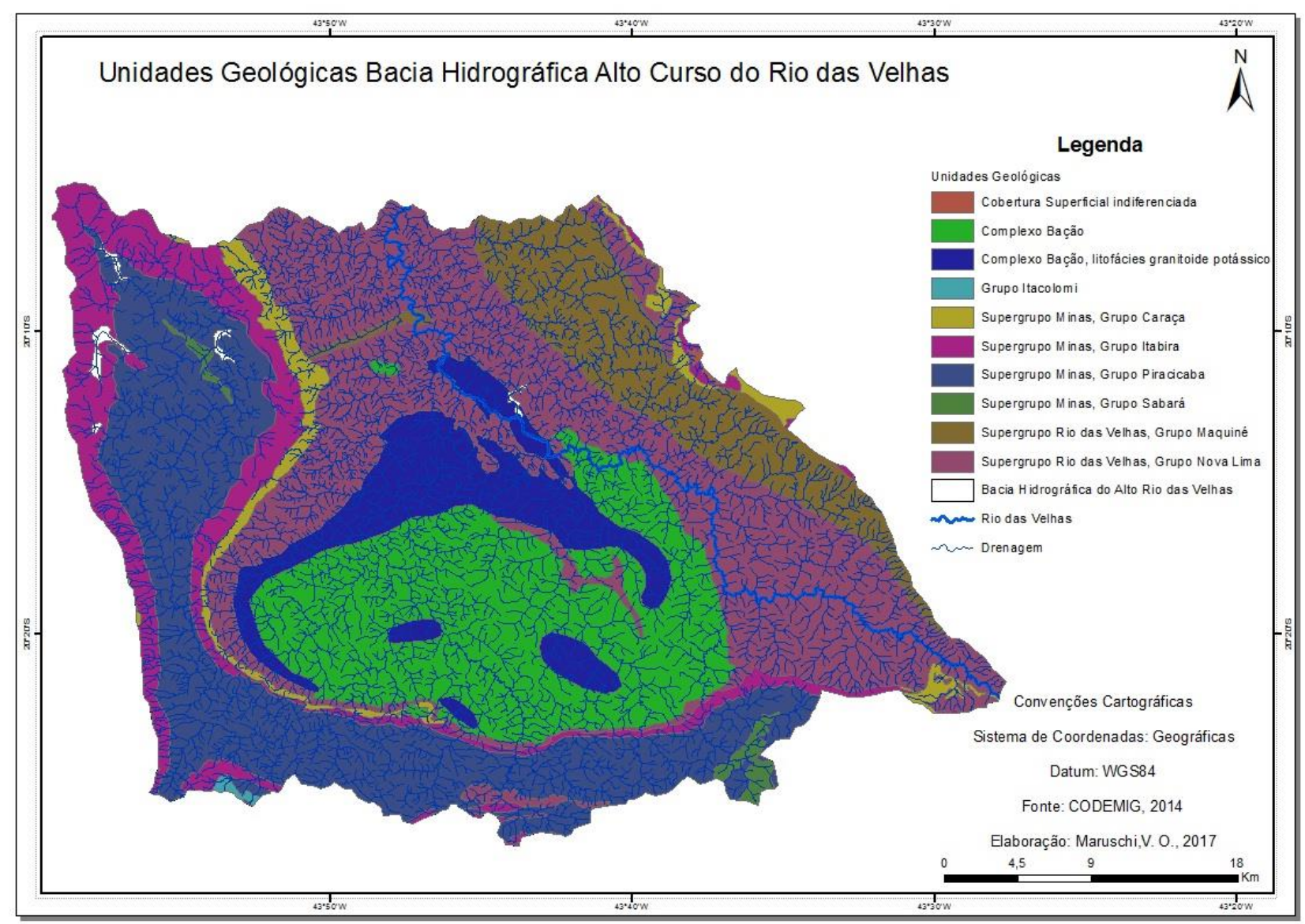

Figura 2 - Unidades Geológicas Bacia Hidrográfica Alto Curso do Rio das Velhas

Diante disso, o objetivo principal deste trabalho é analisar o perfil longitudinal da nascente principal do Rio das Velhas e relacionar dados obtidos a partir dos resultados do perfil longitudinal e da litologia, com a finalidade de encontrar anomalias na extensão analisada do canal.

\section{Fundamentação Teórica}

A Geomorfologia é a ciência que se ocupa das formas da Terra, ela é uma derivação das disciplinas que descreviam a Terra como a orografia, corografia e fisiografia, quando essas disciplinas passam a não apenas a descrever mas tentar explicar as formas da Terra no século XIX é que surge a Geomorfologia. (PENTEADO, 1983)

O objeto de estudo da Geomorfologia são as formas de relevo, o estudo das formas de relevo interfere em estudar os processos ou grupos de processos por trás das formas, estudando o relevo atual podemos 
identificar a dinâmica da topografia atual sobre os diferentes tipos de aspectos que interferem na formação do relevo, e observando o presente podemos associar com processos ocorridos no passado.

Segundo Cunha (1994) está englobado dentro da Geomorfologia Fluvial o estudo dos cursos de água e das bacias hidrográficas. $\mathrm{O}$ estudo dos cursos de água se detém nos processos fluviais e nas formas que é resultado do escoamento das águas, já o segundo estuda as características das bacias que condicionam o regime hidrológico.

Os principais processos que interfere nos cursos d'água são a velocidade da corrente, a declividade e sinuosidade do canal, largura, os sedimentos carregados, características físicas dos sedimentos e os processos antrópicos. Com o avanço da Engenharia a sociedade tem aumentado sua interferência sobre a Geomorfologia Fluvial, criando canais artificiais e artificializando canais naturais.

A utilização de alguns parâmetros morfométricos podem ser usados para auxiliar na quantificação, na caracterização e na fundamentação teórica sobre alterações ou anomalias. (CAMOLEZI; FORTES; MANIERI, 2012). Para melhor entendimento da dinâmica dos recursos das bacias hidrográficas é importante a coleta e análise de dados das características morfométricas, pois essas características possuem uma grande importância nos processos como infiltração, evaporação, quantidade de água transportada pelo canal e abastecimento de aquíferos.

A declividade ou gradiente de um rio é mostrada pelo perfil longitudinal, que é a expressão da relação entre seu comprimento e sua altimetria. O perfil típico é o côncavo, com declividades maiores em direção da nascente, e no nível de base com valores cada vez mais suaves. São considerados em equilíbrio os cursos de água que apresentam tais características. (CHRISTOFOLETTI, 1980; CUNHA, 1994).

Para Christofoletti (1980) o perfil longitudinal resulta do trabalho que o rio tem para manter o equilíbrio entre a capacidade, competência, a quantidade e o calibre da carga de detritos. O rio deverá abaixar sua capacidade e competência através de modificações na morfologia e declividade do canal caso a capacidade e competência seja maiores que as requeridas para transportar a carga que é fornecida. Caso a carga seja menor o rio deverá aumenta-la através de modificações na morfologia e declividade do canal.

Segundo Hack (1973) o Índice de Hack reflete a energia e competência do curso de água e constitui simples produto da declividade do canal em um ponto determinado e o comprimento do canal ao longo da sua maior extensão a partir desse ponto (apud FONSECA; AUGUSTINM; BEZERRA 2013, p. 2).

O Índice de Hack pode ser definido através da energia específica de cada trecho de um canal, essa energia pode variar e criar anomalias dependendo da situação litológica do trecho do canal, e se existir a presença de falhas ou com a existência de quedas e represamento. 


\section{Metodologia}

28 de Junho à 02 de Julho de 2017

Para a análise de perfil longitudinal e Índice de Hack do Rio das Velhas foi utilizado o Software Google Earth Pro para obtenção de dados como: distância do divisor de águas da nascente, perfil longitudinal, diferença de altitude, distância em linha reta e largura do canal utilizando as ferramentas régua, caminho e perfil de elevação, e a utilização do software Excel para tratamento de dados obtidos com o Software Google Earth Pro.

A metodologia apresentada por Cooley, S. W.(2015) nos propõe a fazer medições dos valores de perfil longitudinal, diferença de altitude, distância em linha reta e largura do canal a cada 2 quilômetros, fazendo 40 medições totalizando 80 quilômetros analisados. Depois de coletado os dados no software Google Earth Pro houve o tratamento dos dados no software Excel, onde conseguimos obter os valores de inclinação do trecho, somatória dos trechos, valor do segmento e Índice de Hack (Figura 3).

Para obter o valor de inclinação foi utilizada a diferença de altitude do começo e fim do trecho e posteriormente divido por 2000 metros, valor este referente ao tamanho do trecho avaliado. A somatória dos trechos é obtida a partir da soma de cada intervalo e o valor do segmento é obtido a partir do acumulo das somatórias dos trechos mais a metade do segmento do canal e a distância do divisor de água da nascente. Sendo assim para calcular o Índice de Hack deve-se multiplicar o valor do segmento pela inclinação, ou seja, a declividade pela extensão do referido trecho.
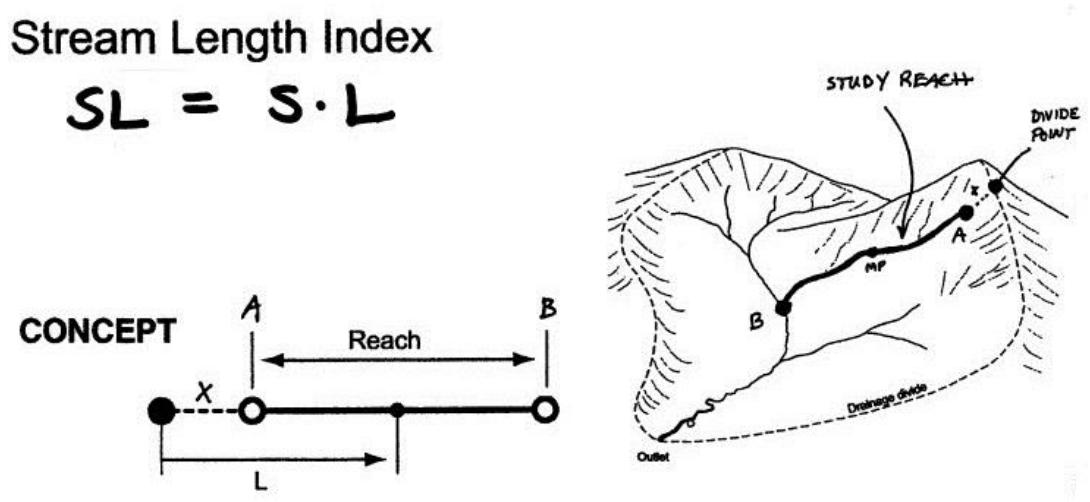

Figura 3: Esquema exploratório sobre o Índice de Hack, Cooley, S. W.(2015)

Foi utilizado para a elaboração do mapa 1 de Localização da bacia Hidrográfica Alto Curso Rio das Velhas, o Software ArcGis 10.2.2 e dados oferecidos pelo IBGE (1970). Já a elaboração do mapa das Unidades Geológicas Bacia Hidrográfica Alto Curso do Rio das Velhas, foi usado o mapa de unidades geológicas disponibilizado pela CODEMIG (2014). Em ambos os mapas foi empregue o Datum: WGS 84. 


\section{Resultados}

Com a obtenção dos dados pelos Softwares Google Earth Pro e ArcGis 10.2.2 elaboramos um gráfico sendo possível analisar e comparar os valores do Índice de Hack e perfil longitudinal com a litologia disponibilizada pela CODEMIG (2014). Analisando a Figura 4 podemos observar que no inicio do canal até o quilometro cinquenta e seis, a litologia encontrada tem a presença do Supergrupo Rio das Velhas, Grupo Nova Lima, Complexo Bação e Complexo Bação litofácieis granitoide potássico, não ocorre variação significativa no valor de Stream Length Index (SL).

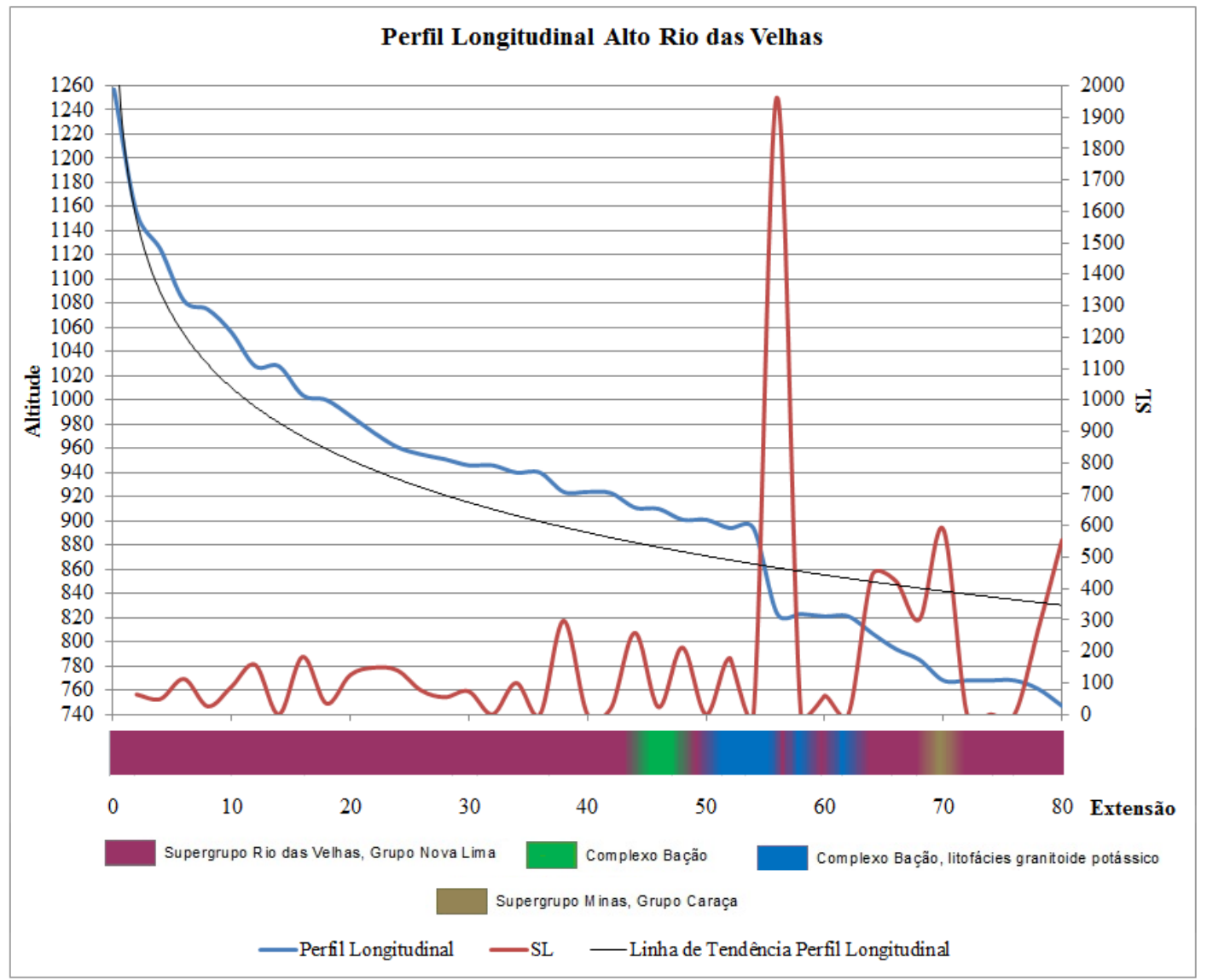

Figura 4 - Perfil Longitudinal Alto Rio das Velhas

Quando ocorre a transição entre o commplexo Bação, litofácieis granitoide potássico para o Supergrupo Rio das Velhas e Grupo Nova Lima no quilômetro cinquenta e seis é que encontramos o maior valor no trecho analisado, a explicação encontrada para esse valor é a troca de uma litologia ígnea para uma litologia metamórfica. No quilômetro sessenta encontramos o segundo menor pico do valor SL, esse baixo valor é o resultado de uma pequena variação na altitude do trecho analisado, essa pequena variação na 


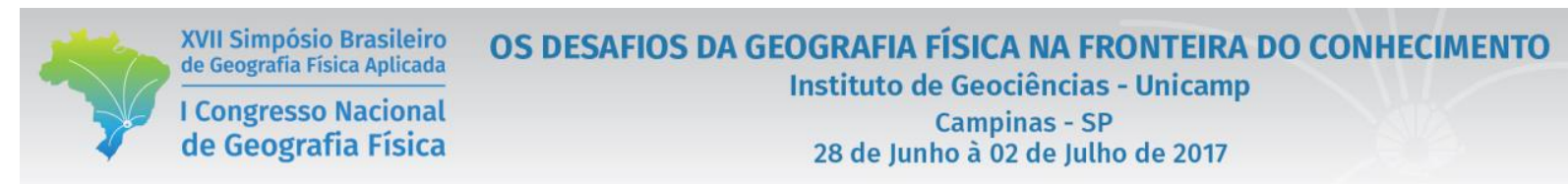

altitude esta relacionada com o encontro de litologias do Complexo Bação litofácieis granitoide potássico e Supergrupo Rio das Velhas, Grupo Nova Lima, o canal utiliza a falha presente no encontro das litologias para fazer seu.

O segundo maior valor obtido no canal se encontra no quilômetro setenta onde o canal passa de uma rocha do Supergrupo Rio das Velhas, Grupo Nova Lima, para o quartzito do Supergrupo Rio das Velhas, Grupo Maquiné, e quando ocorre o contrário sendo a passagem do Supergrupo Rio das Velhas e grupo nova lima no quilômetro setenta e dois encontramos o menor valor de SL no trecho analisado.

\section{Considerações Finais}

Os resultados encontrados permitem interpretar os dados de SL e perfil longitudinal com a litologia da Bacia Hidrográfica Alto Curso do Rio das Velhas, nos mostra também que é possível calcular os valores usando simples ferramentas disponíveis no Software Google Earth Pro e com os valores obtidos comparar com a litologia. Além disso, é possível fazer correções em mapas geológicos utilizando o índice de Hack, pois observamos que quando a troca de litologia os valores SL sofre uma grande variação, essa que geralmente é encontrada em trechos de 2 quilômetros com uma diferença de altitude. Foi encontrado grandes dificuldades para encontrar publicações abordando o tema da forma que ele foi proposto. Um problema encontrado foi com a precisão dos dados disponibilizados pelo Software Google Earth Pro, mas a precisão fornecida foi a suficiente para a elaboração do trabalho.

\section{Agradecimentos}

Agradecemos a FAPEMIG pelo apoio a participação no XVII SBGFA.

\section{Referências}

CAMOlEZI, B.A.; FORTES, E.; MANIERI, D.D. Controle Estrutural Da Rede De Drenagem Com Base Na Correlacao De Dados Morfometricos E Morfoestruturais: O Caso Da Bacia Do Ribeirao Sao Pedro . Parana. Revista Brasileira de Geomorfologia, Sao Paulo, v. 13, n. 2, p. 201-211, abr/jun 2012. Disponível em: < http://www.lsie.unb.br/rbg/index.php/rbg/issue/view/25 > Acesso em: 14/03/2017.

CHRISTOFOLETTI, A. Geomorfologia. 2a Edicao. Sao Paulo: Edgard Blucher, 1980. 188 p

CHRISTOFOLETTI, A. Geomorfologia Fluvial. Sao Paulo: Edgard Blucher, 1981. 313 p

CODEMIG - Companhia de Desenvolvimento Econômico de Minas Gerais. Mapa Geológico do Estado de Minas Gerais. Belo Horizonte: CODEMIG, 2014. Escala 1:1. 000.000.

COOLEY, S. W. Channel Analysis Project. [S.1.]. 2015. Disponível em: < http://gis4geomorphology.com/channelanalysis-project/ > Acesso em: 14/03/2017 


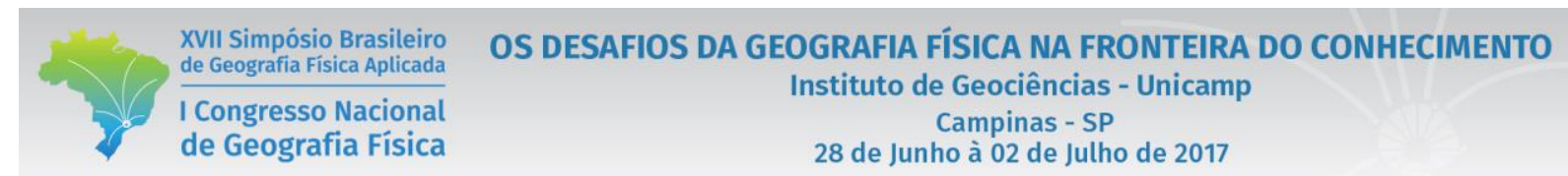

CUNHA, S.B.; GUERRA, A.J.T (Org.). Geomorfologia do Brasil. 6a Edição. Rio de Janeiro: Bertrand Brasil, 2010. 390 p.

FONSECA, B.M.; AUGUSTINM, C.H.R.R.; BEZERRA, D.P. Analise De Perfis Longitudinais Na Bacia Hidrográfica Do Alto Jequitinhonha. Serra Do Espinhaço Meridional/MG. Territorium Terram São Joao Del Rei, v. 01, n. 02, p. 2-8, Abr./Set. 2013/2014. Disponível em: <http://www.seer.ufsj.edu.br/index.php/territorium_terram> Acesso em: 14/03/2017

PENTEADO, M.M. Fundamentos de Geomorfologia. Rio de Janeiro: IBGE, 1983. p. 1-10. 